\title{
The combination of NVP-BEZ235 and rapamycin regulates nasopharyngeal carcinoma cell viability and apoptosis via the PI3K/AKT/mTOR pathway
}

\author{
HUI LUO ${ }^{1 *}$, YU-YU YU ${ }^{1 *}$, HONG-MEI CHEN ${ }^{2}$, WEI WU ${ }^{1}$, YONG LI $^{1}$ and HONG LIN ${ }^{1}$ \\ ${ }^{1}$ Department of Oncology, The First Affiliated Hospital of Nanchang University, Nanchang, Jiangxi 330006; \\ ${ }^{2}$ Department of Oncology, The First Affiliated Hospital of Gannan Medical University, Ganzhou, Jiangxi 341000, P.R. China
}

Received August 24, 2017; Accepted September 4, 2018

DOI: $10.3892 /$ etm.2018.6896

\begin{abstract}
Nasopharyngeal carcinoma (NPC) is a rare malignancy with a remarkable geographical distribution. Regarding NPC treatment, improving the survival rate of advanced patients seems promising. Phosphoinositide 3-kinase (PI3K)/protein kinase B (AKT)/mammalian target of rapamycin (mTOR) pathway deregulation is closely associated with tumorigenesis. In the present study, the NPC cell line SUNE1 was divided into four groups: Control, NVP-BEZ235, rapamycin, and NVP-BEZ235+rapamycin. SUNE1 cells in the NVP-BEZ235 group were incubated with NVP-BEZ235; cells in the rapamycin group were incubated with rapamycin, whereas the NVP-BEZ235+rapamycin group refers to SUNE1 cells incubated with a mixture of NVP-BEZ235 and rapamycin. The control group was treated with the same amount of vehicle. Morphological, MTT, terminal deoxynucleotidyl-transferase-mediated dUTP nick end labeling and flow cytometry assays demonstrated that NVP-BEZ235 and rapamycin caused morphological changes, inhibited cell viability and induced cellular apoptosis. In addition, reverse transcription-quantitative polymerase chain reaction and western blot revealed that the combination of NVP-BEZ235 and rapamycin affected the activation of the $\mathrm{PI} 3 \mathrm{~K} / \mathrm{AKT} / \mathrm{mTOR}$ pathway. The combination of NVP-BEZ235 and rapamycin significantly improved the effect of the drug
\end{abstract}

Correspondence to: Dr Hong Lin, Department of Oncology, The First Affiliated Hospital of Nanchang University, 17 Yongwaizheng Street, Nanchang, Jiangxi 330006, P.R. China

E-mail: linhong973@163.com

"Contributed equally

Abbreviations: NPC, nasopharyngeal carcinoma; PI3K, phosphoinositide 3-kinase; AKT, protein kinase B; mTOR, mammalian target of rapamycin; FACS, fluorescence-activated cell sorting

Key words: nasopharyngeal carcinoma, NVP-BEZ235, rapamycin, cell viability, cell apoptosis therapy. The potential underlying mechanism may comprise the joint effects of inhibiting cell viability, promoting cellular apoptosis and reducing relative signal protein expression levels in SUNE1 cells. These findings provided novel evidence that NVP-BEZ235 suppresses NPC development, and indicated a promising potential application of combination drug therapy (NVP-BEZ235+rapamycin) for the clinical treatment of NPC.

\section{Introduction}

Nasopharyngeal carcinoma (NPC) is a highly invasive and metastatic head and neck cancer (1). NPC is associated with many factors, including Epstein-Barr virus infection, genetic and environmental factors (2). Although radiotherapy is effective for early-stage tumors, patients with advanced NPC succumb to skull base and neck lymph node invasion and metastasis (3). It is reported that the median survival of patients with metastatic or advanced NPC is only 5-11 months (4). The poor prognosis is mainly due to high recurrence and metastasis rates (5). Consequently, there is an urgent requirement to explore new therapies against NPC.

Phosphoinositide 3-kinase (PI3K)/protein kinase B (AKT)/mammalian target of rapamycin (mTOR) signaling is commonly associated with tumorigenesis (6). During the development of tumors, PI3K pathway deregulation commonly occurs via the inactivation of the tumor suppressor phosphatase and tensin homolog (7), and mTOR is activated and associated with cell growth, proliferation, differentiation and apoptosis (8). Thus, the PI3K/AKT/mTOR pathway provides a promising target for cancer therapy. NVP-BEZ235 is an imidazo [4,5-c]quinoline derivative and suppresses the activities of PI3K and mTOR (9). Previous reports have demonstrated that NVP-BEZ235 exerts an anti-cancer function in breast cancer (10), ovarian cancer (11) and prostate cancer (12). Although NVP-BEZ235 has been used in patients with advanced NPC for phase I/II clinical trials, the outcomes of these trials have been unsatisfactory (13).

Rapamycin, as an mTOR signaling inhibitor, reduces cell proliferation in NPC (1). The main aim of the present study was to investigate the role of the combination of NVP-BEZ235 and rapamycin on NPC cell viability, cellular apoptosis and $\mathrm{PI} 3 \mathrm{~K} / \mathrm{AKT} / \mathrm{mTOR}$ signaling. The results indicated that both 
NVP-BEZ235 and rapamycin caused morphological changes, inhibited cell viability, induced cellular apoptosis and affected the activation of the PI3K/AKT/mTOR pathway. The combination of NVP-BEZ235 and rapamycin significantly improved the effects of the drug therapy. Therefore, the present study identified potential novel anti-NPC drugs with more efficiency and less toxicity.

\section{Materials and methods}

Cell culture. The NPC cell line SUNE1 was obtained from Wuxi Innovate Biomedical Technology Co.,Ltd. (Wuxi, China). SUNE1 cells were incubated with Dulbecco's modified Eagle's medium (Gibco; Thermo Fisher Scientific, Inc., Waltham, MA, USA) containing 10\% fetal bovine serum (Gibco; Thermo Fisher Scientific, Inc.) at $37^{\circ} \mathrm{C}$. SUNE1 cells were seeded into a 24-well plate at the density of $80 \%$, and then were incubated with 100 nM NVP-BEZ235 (cat. no. A506167) (14), 100 nM rapamycin (cat. no. A606203; both Sangon Biotech Co., Ltd., Shanghai, China) (15), or $100 \mathrm{nM}$ NVP-BEZ235 and $100 \mathrm{nM}$ Rapamycin for $48 \mathrm{~h}$ at $37^{\circ} \mathrm{C}$. The control group was administered the same amount of dimethyl sulphoxide (DMSO; Sangon Biotech Co., Ltd.). Cell morphology following treatment was observed with an inverted phase contrast microscope (Olympus Corporation, Tokyo, Japan; magnification, x100).

Cellular apoptosis detected by terminal deoxynucleotidyl-transferase-mediated dUTP nick end labeling (TUNEL) assay and flow cytometry. SUNE1 cells from the four groups were fixed with $4 \%$ paraformldehyde at room temperature for $5 \mathrm{~min}$, washed with PBS and incubated with $50 \mathrm{~mL}$ TUNEL detection solution ( $2 \mathrm{ml}$ terminal deoxynucleotidyl-transferase enzyme and digoxigenin-dUTP reaction buffer) at $37^{\circ} \mathrm{C}$ for $1 \mathrm{~h}$. Following washing with PBS, SUNE1 cells were stained with DAPI $(1 \mathrm{mg} / \mathrm{ml})$ in PBS for $10 \mathrm{~min}$ at room temperature. A total of 5 non-overlapping fields were captured with a fluorescence inverted microscope (Bio-Rad Laboratories, Inc., Hercules, CA, USA; magnification, x100).

For the flow cytometry assay, SUNE1 cells from the four groups were washed with PBS twice, and incubated with $400 \mathrm{ml} 1 \mathrm{X}$ binding buffer and $5 \mathrm{ml}$ fluorescein isothiocyanate-labeled Annexin-V from the Annexin V-FITC/PI kit (cat. no. APOAF-20TST; Sigma-Aldrich; Merck KGaA, Darmstadt, Germany) for $15 \mathrm{~min}$ in the dark at room temperature. Then, SUNE1 cells were incubated with $10 \mathrm{ml}$ propidium iodide for $5 \mathrm{~min}$ in the dark at room temperature. Cellular apoptosis was detected with fluorescence-activated cell sorting (FACS) using FCSExpress version 3.0 (De Novo Software, Glendale, CA, USA) in a flow cytometer (BD FACSCalibur; BD Biosciences, Franklin Lakes, NJ, USA).

Cell viability examined by MTT assay and flow cytometry. SUNE1 cells in the exponential growth phase were collected and seeded in a 96-well plate at $5 \times 10^{3}$ cells/well in $100 \mathrm{ml}$ culture medium. Cells were incubated with NVP-BEZ235 and/or rapamycin at final concentrations of $100 \mathrm{nM}$ for $48 \mathrm{~h}$ at $37^{\circ} \mathrm{C}$, in the groups detailed above. Following incubation, the medium was removed and $100 \mathrm{ml}$ fresh medium containing $10 \%$ MTT $(5 \mathrm{mg} / \mathrm{ml}$ ) was added into each well. Following $4 \mathrm{~h}$ of incubation at $37^{\circ} \mathrm{C}$, DMSO $(200 \mathrm{ml})$ was added to cells for
$10 \mathrm{~min}$ and the absorbance was measured at $570 \mathrm{~nm}$ using a multifunctional microplate reader (Thermo Fisher Scientific, Inc.). To calculate the relative cell viability, 6-well replication was used. Data were analyzed in three independent samples.

SUNE1 cells from the four groups were digested with trypsin and fixed with $70 \%$ ethanol overnight at $4^{\circ} \mathrm{C}$. The following morning, SUNE1 cells were washed with PBS and subsequently stained with propidium iodide $(50 \mathrm{mg} / \mathrm{ml})$ and RNase A (100 mg/ml; cat. no. B300068; Sangon Biotech Co., Ltd.) for $1 \mathrm{~h}$ in the dark. The cell cycle was analyzed FACS using FCSExpress software in BD FACSCalibur flow cytometer.

Reverse transcription-quantitative polymerase chain reaction $(R T-q P C R)$. Total RNA was extracted from SUNE1 cells using TRIzon Reagent (Beijing ComWin Biotech, Co., Ltd., Beijing, China). The quality and quantity of RNA was examined with a NanoDrop-2000 ultramicrospectrophotometer (NanoDrop; Thermo Fisher Scientific, Inc., Wilmington, DE, USA) at wavelengths of 260 and $280 \mathrm{~nm}$. Subsequently, $1 \mathrm{mg}$ RNA was reverse transcribed into cDNA using the SuperRT cDNA Synthesis kit (Beijing ComWin Biotech, Co., Ltd.) according to the manufacturer's protocol, and qPCR was carried out with SYBR Green qPCR SuperMix (Invitrogen; Thermo Fisher Scientific, Inc.) in CFX96 ${ }^{\mathrm{TM}}$ Real-Time PCR Detection system (Bio-Rad Laboratories, Inc.). The thermocycling conditions were as follows: $95^{\circ} \mathrm{C}$ for $5 \mathrm{~min}$, followed by 40 cycles of $95^{\circ} \mathrm{C}$ for $30 \mathrm{sec}$ and $60^{\circ} \mathrm{C}$ for $30 \mathrm{sec}$, and a final extension at $72^{\circ} \mathrm{C}$ for $5 \mathrm{~min}$. The relative expression of genes was normalized to GAPDH using the $2^{-\Delta \Delta \mathrm{Cq}}$ method (16). The primers for RT-qPCR were as follows: GAPDH forward, 5'-TGACTT CAACAGCGACACCCA-3' and reverse, 5'-CACCCTGTT GCTGTAGCCAAA-3'; PI3K forward, 5'-GCCCAGGCT TACTACAGAC-3' and reverse, 5'-AAGTAGGGAGGCATC TCG-3'; AKT forward, 5'-CTCATTCCAGACCCACGAC-3' and reverse, 5'-ACAGCCCGAAGTCCGTTA-3'; and mTOR forward, 5'-CTGGGACTCAAATGTGTGCAGT-3' and reverse, 5'-GAACAATAGGGTGAATGATCCGGG-3'.

Western blotting. Proteins were extracted using radioimmunoprecipitation assay lysis buffer (Santa Cruz Biotechnology, Inc., Dallas, TX, USA) and centrifuged at $12,000 \mathrm{x} \mathrm{g}$ at $4^{\circ} \mathrm{C}$ for $20 \mathrm{~min}$. The concentration of protein was detected with a bicinchoninic acid kit (Pierce; Thermo Fisher Scientific, Inc.), according to the manufacturer's protocol. Subsequently, 30-50 mg protein was subjected to SDS-PAGE on a $10 \%$ gel and transferred to a polyvinylidene difluoride membrane (EMD Millipore, Billerica, MA, USA). Following blocking with $5 \%$ non-fat milk in Tris-buffered saline containing $0.05 \%$ Tween-20 (TBST) at room temperature for $1 \mathrm{~h}$, the membranes were probed with the following mouse monoclonal antibodies: Anti-PI3K (ab86714; 1:1,000), anti-AKT (ab175354; 1:1,000), anti-phosphorylated (p)-AKT (ab105731; 1:500), anti-mTOR (ab87540; 1:1,000), anti-GAPDH (AB8245; 1:1,000) and rabbit monoclonal anti-p-mTOR (ab109268; 1:1,000; all Abcam, Cambridge, MA, USA) at $4^{\circ} \mathrm{C}$ overnight. The membranes were incubated with the rabbit anti-mouse IgG (ab6728; 1:10,000) or goat anti-rabbit IgG (ab205718; 1:10,000) horseradish peroxidase-labeled secondary antibodies (both Abcam) at room temperature for $1 \mathrm{~h}$. Following washing with TBST, the blot was examined with electrochemiluminescence 

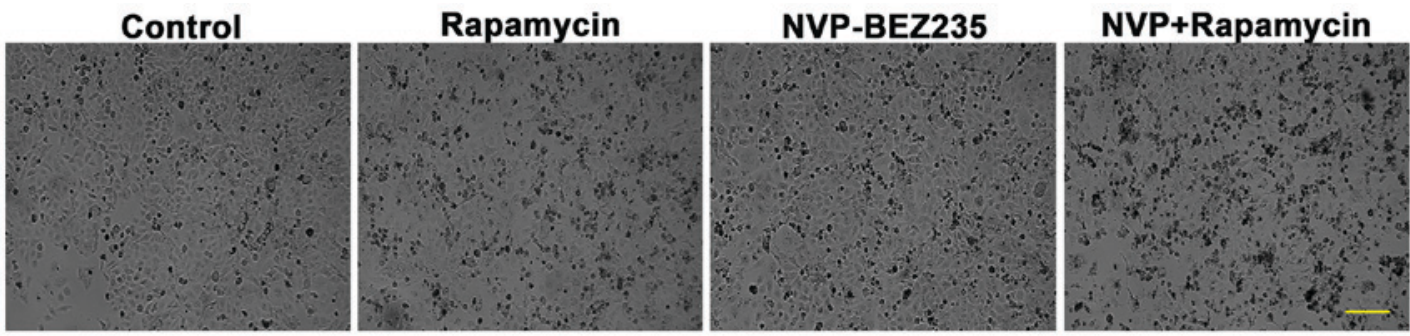

Figure 1. NVP-BEZ235 and rapamycin affected cellular morphological changes. SUNE1 cells were placed into a 24-well plate and cultured with $100 \mathrm{nM}$ NVP-BEZ235, $100 \mathrm{nM}$ rapamycin, or $100 \mathrm{nM}$ NVP-BEZ235 and $100 \mathrm{nM}$ rapamycin. The control group was administered the same amount of vehicle. Following $48 \mathrm{~h}$, cells were collected for morphological analysis by inverted phase contrast microscopy. Compared with the control group, the addition of NVP-BEZ235 and rapamycin inhibited the growth of SUNE1. Scale bar, $100 \mu \mathrm{m}$. NVP, NVP-BEZ235.

solution (Pierce; Thermo Fisher Scientific, Inc.). The relative expression was normalized to GAPDH using Quantity One software version 4.2 (Bio-Rad Laboratories, Inc.).

Statistical analysis. Statistical analysis was performed with SPSS 17.0 (SPSS, Inc., Chicago, IL, USA). All experiments were carried out at least three times. Data are expressed as the mean \pm standard deviation, and differences were analyzed using one-way analysis of variance with Tukey's post-hoc test. $\mathrm{P}<0.05$ was considered to indicate a statistically significant difference.

\section{Results}

Rapamycin and NVP-BEZ235 promote cellular apoptosis. As presented in Fig. 1, cells in the control group possessed clear cell contours, boundaries and round cellular nuclei, with good cell growth status. However, once SUNE1 cells were incubated with NVP-BEZ235 or rapamycin, they exhibited shrinkage and cell size reduction. Furthermore, more marked morphological changes were observed in NVP-BEZ235+rapamycin induced cells. These data suggested that the above drugs inhibited the growth of SUNE1 cells.

To further examine the effect of NVP-BEZ235 and rapamycin on SUNE1 cellular apoptosis, TUNEL and flow cytometry assays were performed. As presented in Fig. 2A, very few apoptotic cells were observed in the control group. However, compared with the control group, the number of TUNEL-positive cells in the NVP-BEZ235 orrapamycin groups was markedly increased, and the number of apoptotic cells in NVP-BEZ235+rapamycin was the greatest. To further validate the results, flow cytometry was performed. As presented in Fig. 2B and C, the trend in the number of early apoptotic cells (the fourth quadrant) and the late apoptotic cells (the second quadrant) was as follows: NVP-BEZ235+rapamycin group $>$ rapamycin group $>$ NVP-BEZ235 group $>$ control group. These data were in accordance with the TUNEL assay results. These results suggested that NVP-BEZ235 and rapamycin induced SUNE1 cellular apoptosis, and the combination enhanced this promoting effect.

Rapamycin and NVP-BEZ235 suppress cell viability. To further explore the role of rapamycin and NVP-BEZ235 on cell viability, MTT and cell cycle distribution assays were performed following the different drugs treatments (Fig. 3). As presented in Fig. 3A, compared with the control group, the cell viability in the NVP-BEZ235 group $(66.76 \pm 2.16 \%)$ and the rapamycin group $(63.92 \pm 2.52 \%)$ was significantly decreased compared with the control group $(\mathrm{P}<0.01)$. In addition, NVP-BEZ235+rapamycin cell survival $(38.15 \pm 1.94 \%)$ was markedly decreased compared with NVP-BEZ235 or rapamycin alone. In Fig. 3B, compared with the control group, the addition of NVP-BEZ235 or rapamycin markedly enhanced the percentage of cells at the G1 phase. The percentage of cells at G1 phage was greatest in the NVP-BEZ235+rapamycin group. These data indicated that NVP-BEZ235 and rapamycin arrested the cell cycle at the G1 phase, and that the drug combination heightened the intensity of the effect.

Rapamycin and NVP-BEZ235 suppress the activation of PI3K/AKT/mTOR pathway. To explore the mechanism by which NVP-BEZ235 and rapamycin affect cellular apoptosis and viability, the expression of PI3K, AKT and mTOR were evaluated (Fig. 4). As presented in Fig. 4A-C, compared with the control group, NVP-BEZ235 significantly suppressed the mRNA levels of PI3K, AKT and mTOR $(\mathrm{P}<0.01)$; rapamycin only significantly decreased the expression of $\operatorname{mTOR}(\mathrm{P}<0.01)$, but had no significant effect on the mRNA levels of PI3K and AKT $(\mathrm{P}>0.05)$. The combination of NVP-BEZ235 and rapamycin exerted more marked inhibition on the mRNA levels of PI3K, AKT and mTOR compared with the control group $(\mathrm{P}<0.01)$. Similarly, the protein levels of PI3K, AKT, p-AKT, mTOR and p-mTOR were detected following the different drugs treatments. As presented in Fig. 4D-K, it was demonstrated that rapamycin suppressed the protein level of p-AKT, mTOR, p-mTOR, p-AKT/AKT, and p-mTOR/mTOR compared with the control group $(\mathrm{P}<0.01)$, but had no significant effect on the expression of AKT and PI3K $(\mathrm{P}>0.05)$. However, NVP-BEZ235 alone significantly repressed the protein levels of PI3K, AKT, p-AKT, mTOR, p-mTOR, p-AKT/AKT and $\mathrm{p}-\mathrm{mTOR} / \mathrm{mTOR}$ compared with the control group $(\mathrm{P}<0.01)$. NVP-BEZ235+rapamycin induced more marked inhibition of PI3K, AKT, p-AKT, mTOR, p-mTOR, p-AKT/AKT and $\mathrm{p}-\mathrm{mTOR} / \mathrm{mTOR}$. Together, these findings suggested that rapamycin and NVP-BEZ235 inhibited the activation of the $\mathrm{PI} 3 \mathrm{~K} / \mathrm{AKT} / \mathrm{mTOR}$ pathway, and the combination of the two drugs promoted the inhibition.

\section{Discussion}

Despite the progress that has been made in researching NPC, the molecular mechanism underlying NPC remains elusive. 
A
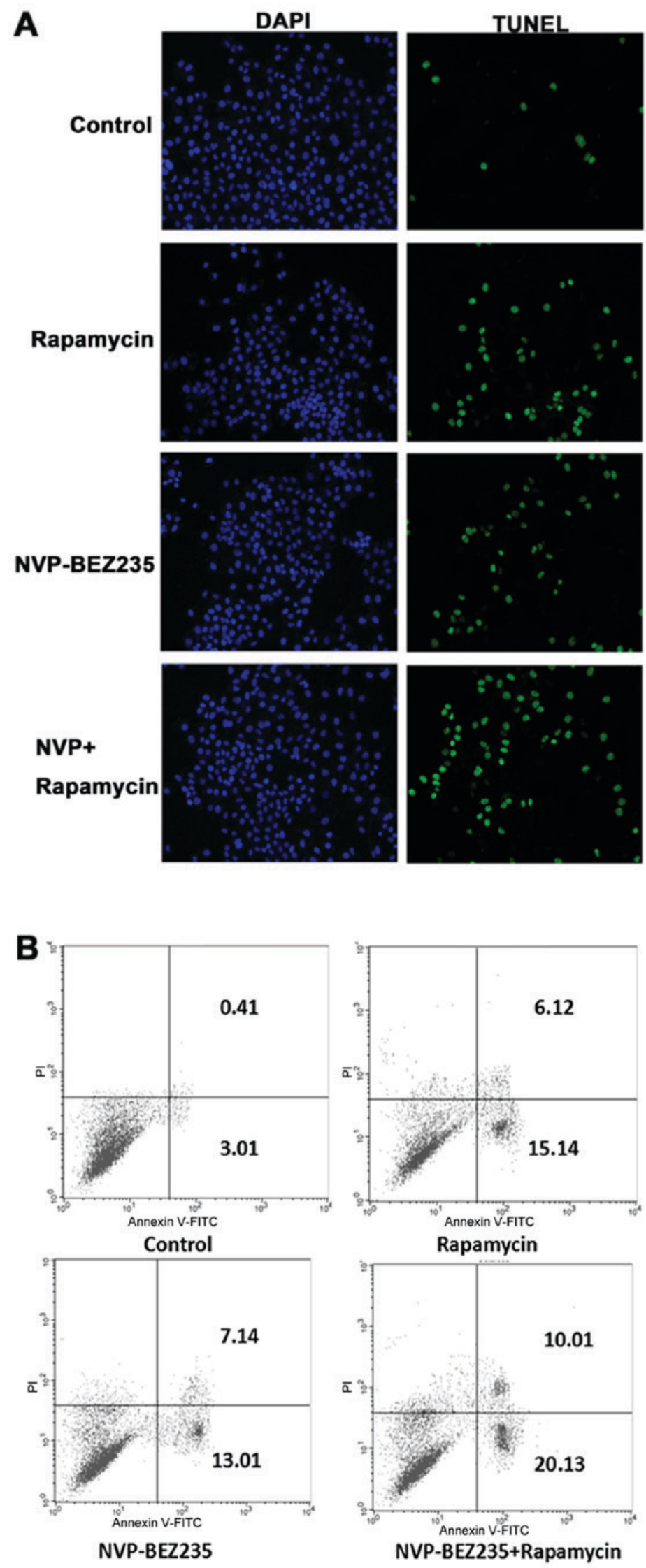
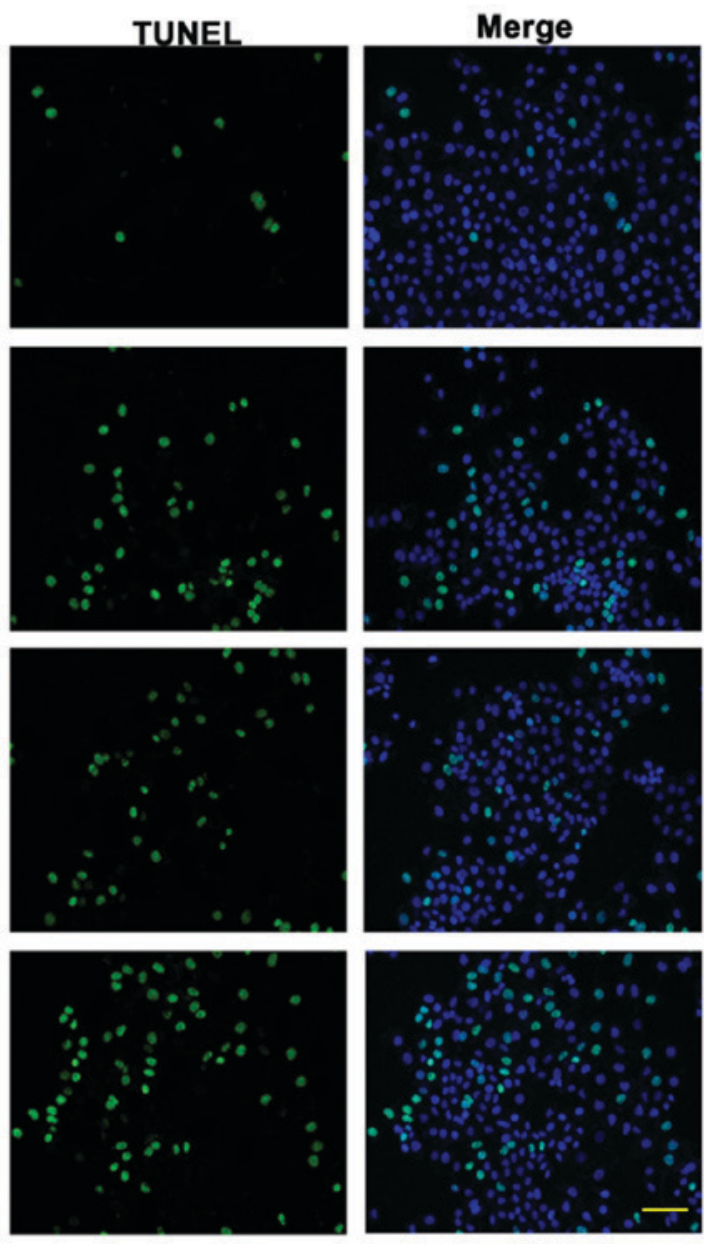

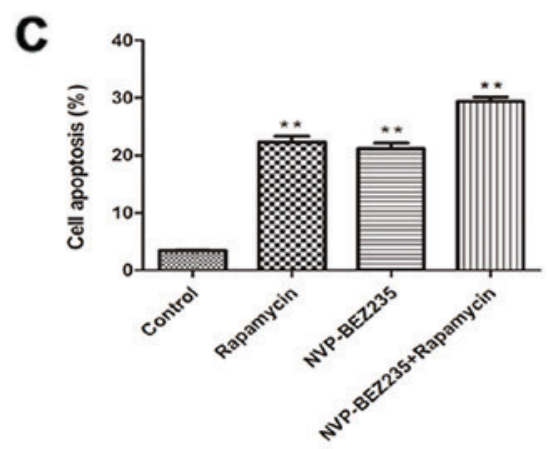

Figure 2. NVP-BEZ235 and rapamycin promoted cellular apoptosis. SUNE1 cells were cultured with $100 \mathrm{nM}$ NVP-BEZ235, $100 \mathrm{nM}$ rapamycin, or $100 \mathrm{nM}$ NVP-BEZ235 and $100 \mathrm{nM}$ rapamycin. The control group was administered the same amount of vehicle. Following $48 \mathrm{~h}$, cells were collected for further experiments. (A) NVP-BEZ235 and rapamycin induced cellular apoptosis, as detected by TUNEL. TUNEL-positive cells were marked green, and nuclei were stained with DAPI in blue. Scale bar, $100 \mu \mathrm{m}$. (B) Cellular apoptosis was detected via flow cytometry. The fourth and second quadrants indicated the early apoptotic cells and the late apoptotic cells, respectively. (C) The percentage of apoptotic cells from different groups is presented. Few apoptotic cells were observed in the control group. The addition of NVP-BEZ235 and rapamycin increased the number of apoptotic cells, and NVP-BEZ235+rapamycin enhanced the effects. ${ }^{* *} \mathrm{P}<0.01$ vs. control. TUNEL, terminal deoxynucleotidyl-transferase-mediated dUTP nick end labeling; NVP, NVP-BEZ235. 

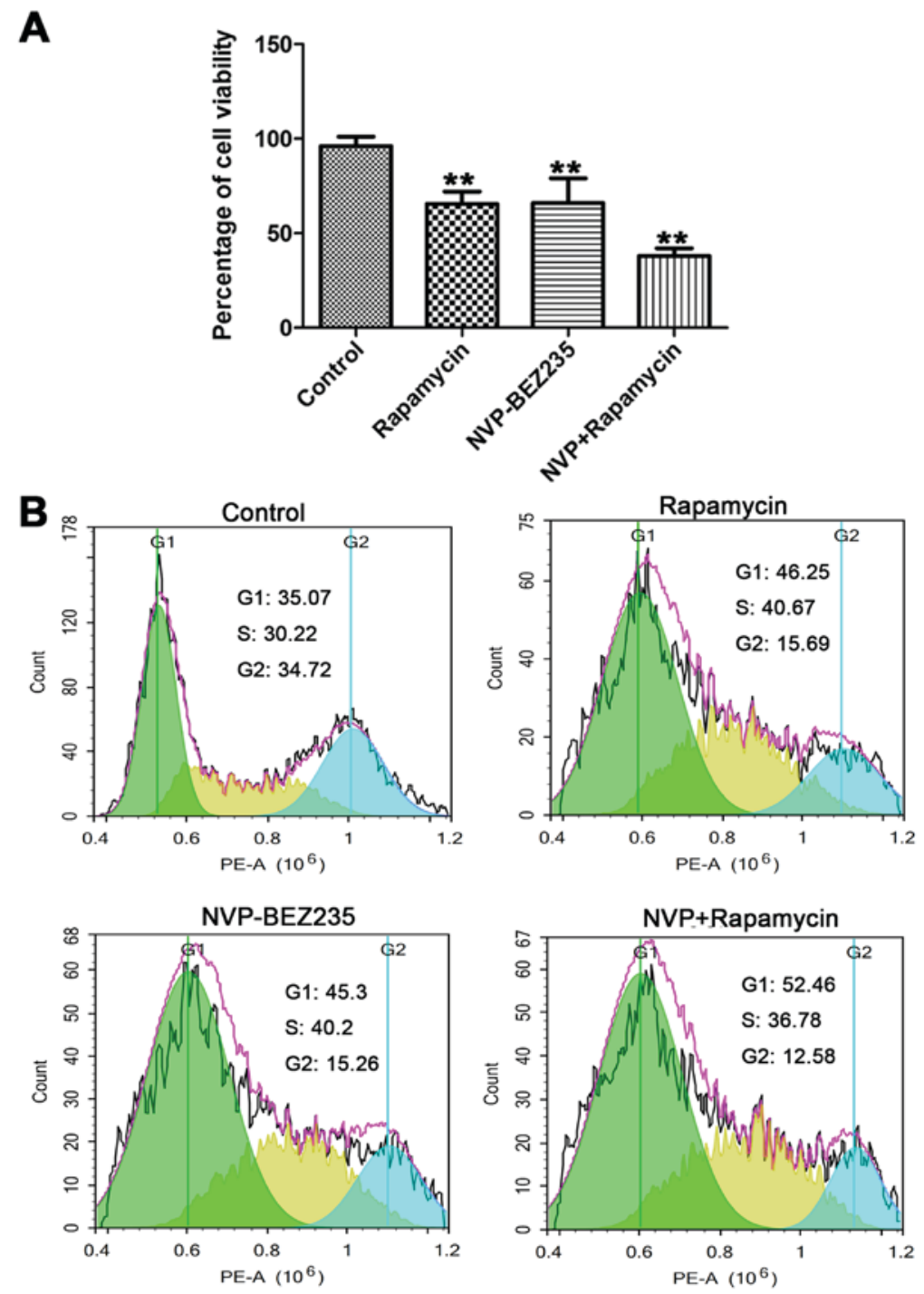

Figure 3. NVP-BEZ235 and rapamycin blocked cell viability. SUNE1 cells were cultured with $100 \mathrm{nM}$ NVP-BEZ235, $100 \mathrm{nM}$ rapamycin, or $100 \mathrm{nM}$ NVP-BEZ235 and $100 \mathrm{nM}$ Rapamycin for $48 \mathrm{~h}$. The control group was administered the same amount of vehicle. (A) NVP-BEZ235+rapamycin significantly blocked cell survival as evaluated by MTT assay. (B) NVP-BEZ235+rapamycin induced cell cycle arrest at G1 phase, as detected by flow cytometry. ${ }^{* *} \mathrm{P}<0.01$ vs. control. NVP, NVP-BEZ235.

A previous study demonstrated that NVP-BEZ235 significantly inhibited cell proliferation in NPC via inhibition of the PI3K/AKT/mTOR pathway (17). However, the outcomes for NVP-BEZ235 in phase I/II clinical trials in advanced patients have been unsatisfactory (13). In the present study, the role of the combination of NVP-BEZ235 and rapamycin on NPC cellular apoptosis, cell viability, and PI3K/AKT/mTOR signaling was investigated, which might provide a novel drug for NPC therapy. The findings suggested that the combination of NVP-BEZ235 and rapamycin significantly induced cellular apoptosis, blocked cell viability and inhibited the activation of $\mathrm{PI} 3 \mathrm{~K} / \mathrm{AKT} / \mathrm{mTOR}$ pathway.

The PI3K/AKT/mTOR signaling pathway is associated with various biological events, including proliferation and apoptosis (18), and provides a good target for cancer treatment (19). NVP-BEZ235 is a synthetic low molecular mass compound and blocks PI3K catalytic activity by competing at its ATP-binding site (10), and represses the catalytic activity of mTOR (20). It has been revealed that AKT acts as a key regulator in PI3K/AKT/mTOR signaling, regulates cell proliferation by monitoring the expression of the cell cycle proteins c-myc and cyclin D1, and mediates cell survival by regulating a cascade of pro-apoptotic and anti-apoptotic proteins (21). However, the application of NVP-BEZ235 significantly suppresses the activation of AKT, S6 ribosomal protein and 4EBP1 in breast cancer (19). In the present study, it was demonstrated that the administration of NVP-BEZ235 significantly promoted cellular apoptosis, repressed cell viability, and modulated the expression of PI3K, AKT, p-AKT, mTOR, p-mTOR, p-AKT/AKT and p-mTOR/mTOR in SUNE1 cells. These data revealed that NVP-BEZ235 regulated NPC development via regulation of the PI3K/AKT/mTOR signaling pathway, which was in accordance with a previous study (9).

mTOR is a serine/threonine kinase which is associated with the PI3K/AKT/mTOR pathway (22). A number of studies have indicated that mTOR regulates the synthesis of key proteins for cell growth and proliferation (23-25). Rapamycin, as an inhibitor of mTOR, significantly inhibits NPC cell proliferation in vitro and the formation of tumors in vivo (26). In the present study, treatment with rapamycin promoted cellular apoptosis, 

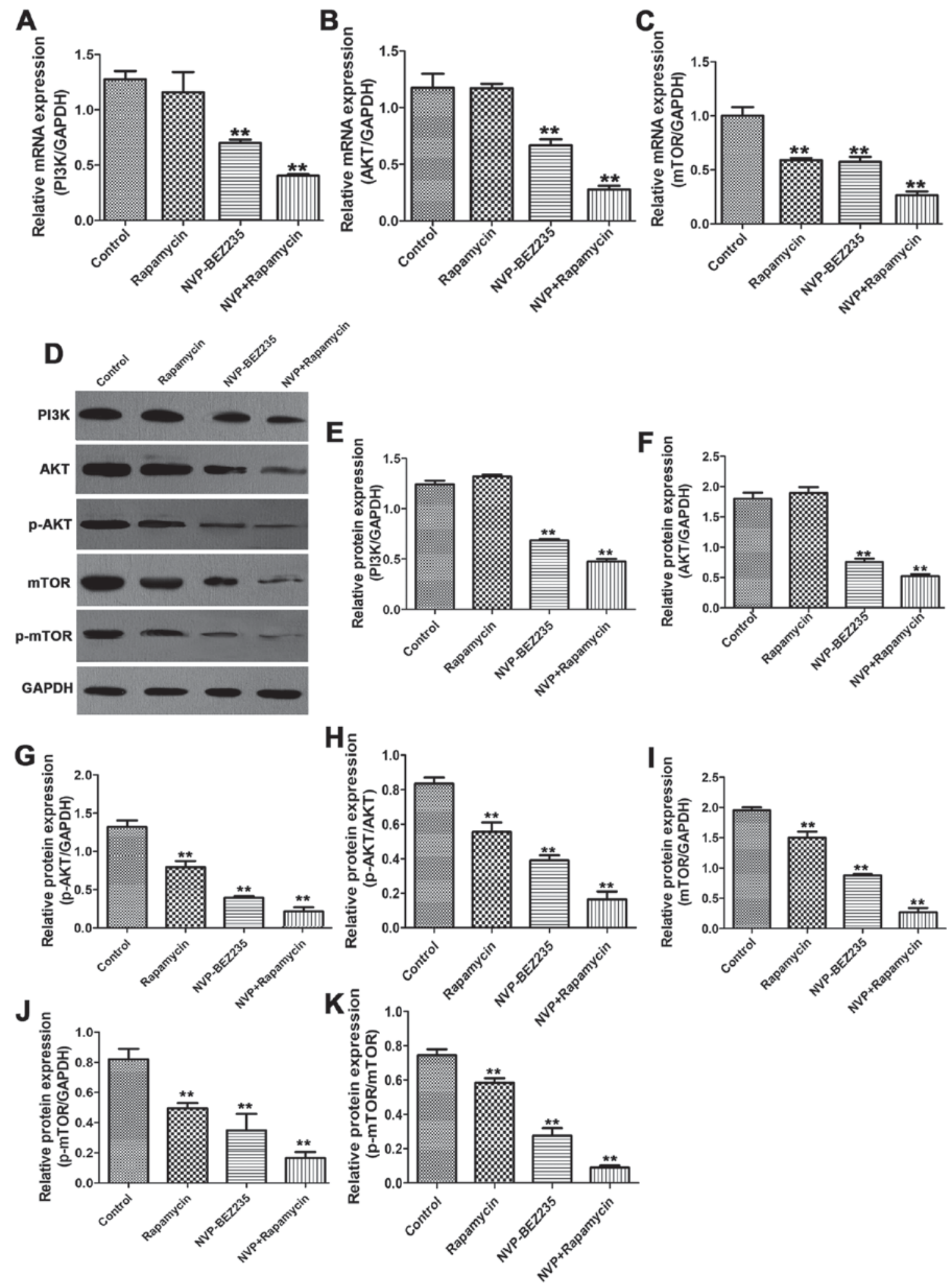

Figure 4. NVP-BEZ235 and rapamycin repressed the PI3K/AKT/mTOR pathway. SUNE1 cells were treated with $100 \mathrm{nM}$ NVP-BEZ235, $100 \mathrm{nM}$ rapamycin, or $100 \mathrm{nM}$ NVP-BEZ235 and $100 \mathrm{nM}$ rapamycin for $48 \mathrm{~h}$. The control group was administered the same amount of vehicle. Total RNA from the four groups was isolated for reverse transcription-quantitative polymerase chain reaction. The mRNA levels of (A) PI3K, (B) AKT and (C) mTOR were normalized to the internal control GAPDH. (D) The protein levels of PI3K, AKT, p-AKT, mTOR and p-mTOR were detected by western blotting. (E-K) The protein density of PI3K, AKT, p-AKT, mTOR and p-mTOR was calculated relative to the internal control GAPDH, and the p-AKT/AKT and p-mTOR/mTOR ratios were calculated. ${ }^{* *} \mathrm{P}<0.01$ vs. control. PI3K, phosphoinositide 3-kinase; AKT, protein kinase B; mTOR, mammalian target of rapamycin; p, phosphorylated; NVP, NVP-BEZ235.

suppressed cell viability and blocked the expression of p-AKT, mTOR, p-mTOR, p-AKT/AKT and p-mTOR/mTOR, but had no effect on the mRNA and protein levels of PI3K and AKT.
These data indicated that rapamycin participated in the inhibition of NPC development by repressing the expression of mTOR, which supported previous findings (1). 
Although previous studies demonstrated that NVP-BEZ235 and rapamycin functioned as therapies for NPC $(2,17)$, the outcome of the single drugs was unsatisfactory. The aim of the present study was to identify a more effective drug for NPC therapy, thus the effect of NVP-BEZ235+rapamycin was detected on SUNE1 cellular apoptosis and viability. In the present study, it was demonstrated that the combination of NVP-BEZ235 and rapamycin more markedly promoted cellular apoptosis and repressed cell viability than either single drug treatment (NVP-BEZ235 or rapamycin alone). Furthermore, the administration of NVP-BEZ235+rapamycin reduced the expression of PI3K, AKT, p-AKT, p-mTOR, p-mTOR, $\mathrm{p}-\mathrm{AKT} / \mathrm{AKT}$ and $\mathrm{p}-\mathrm{mTOR} / \mathrm{mTOR}$. Thus, it was concluded that the combination of NVP-BEZ235 and rapamycin modulated cell viability and apoptosis via the PI3K/AKT/mTOR pathway in SUNE1 cells; and that the outcome with the two drugs was more positive than with either single drug. These results provided insight for exploring novel drug therapies for NPC.

However, there were certain limitations in the present study. First, the effect of NVP-BEZ235+rapamycin was evaluated in SUNE1 cells with a lack of in vivo animal experiments. Therefore, authors may perform further studies on the effect of NPV-BEZ235+rapamycin on animals in vivo, which may provide important findings for a future clinical trial. Secondly, although it was demonstrated that NVP-BEZ235+rapamycin modulated cell viability and apoptosis via the PI3K/AKT/mTOR pathway, the molecular mechanism by which NPV-BEZ235+rapamycin regulated the $\mathrm{PI} 3 \mathrm{~K} / \mathrm{AKT} / \mathrm{mTOR}$ pathway remains elusive. Further investigations are required to elucidate this mechanism.

\section{Acknowledgements}

Not applicable.

\section{Funding}

The present study was supported by Jiangxi Science and Technology Department Supoort Project (grant no. 20151BBG70233).

\section{Availability of data and materials}

All data generated or analyzed during this study are included in this published article.

\section{Authors' contributions}

HLu and Y-YY analyzed the data and were major contributors in writing the manuscript. H-MC cultured the cells, performed the cell apoptosis and cell cycle distribution detection via flow cytometry, and prepared Figs. 1, 2 and 3. WW and YL performed the RNA and protein extraction for reverse transcription-quantitative polymerase chain reaction and western blot analyses, respectively, and prepared Fig. 4. HLi directed the study and revised the manuscript.

\section{Ethics approval and consent to participate}

Not applicable.

\section{Patient consent for publication}

Not applicable.

\section{Competing interests}

The authors declare that they have no competing interests.

\section{References}

1. Yang C, Zhang Y, Zhang Y, Zhang Z, Peng J, Li Z, Han L, You Q, Chen X, Rao X, et al: Downregulation of cancer stem cell properties via mTOR signaling pathway inhibition by rapamycin in nasopharyngeal carcinoma. Int J Oncol 47: 909-917, 2015.

2. Lo KW, To KF and Huang DP: Focus on nasopharyngeal carcinoma. Cancer Cell 5: 423-428, 2004.

3. Shueng PW, Shen BJ, Wu LJ, Liao LJ, Hsiao CH, Lin YC, Cheng PW, Lo WC, Jen YM and Hsieh CH: Concurrent image-guided intensity modulated radiotherapy and chemotherapy following neoadjuvant chemotherapy for locally advanced nasopharyngeal carcinoma. Radiat Oncol 6: 95, 2011.

4. Lee AW, Ng WT, Chan YH, Sze H, Chan C and Lam TH: The battle against nasopharyngeal cancer. Radiother Oncol 104: 272-278, 2012.

5. Stoker SD, van Diessen JN, de Boer JP, Karakullukcu B, Leemans CR and Tan IB: Current treatment options for local residual nasopharyngeal carcinoma. Curr Treat Options Oncol 14: 475-491, 2013.

6. Chen YH, Wei MF, Wang CW, Lee HW, Pan SL, Gao M, Kuo SH, Cheng AL and Teng CM: Dual phosphoinositide 3-kinase/mammalian target of rapamycin inhibitor is an effective radiosensitizer for colorectal cancer. Cancer Lett 357: 582-590, 2015.

7. Li JR, Cheng CL, Yang CR, Ou YC, Wu MJ and Ko JL: Dual inhibitor of phosphoinositide 3-kinase/mammalian target of rapamycin NVP-BEZ235 effectively inhibits cisplatin-resistant urothelial cancer cell growth through autophagic flux. Toxicol Lett 220: 267-276, 2013

8. Yuan TL and Cantley LC: PI3K pathway alterations in cancer: Variations on a theme. Oncogene 27: 5497-5510, 2008.

9. Hong SW, Shin JS, Moon JH, Kim YS, Lee J, Choi EK, Ha SH, Lee DH, Chung HN, Kim JE, et al: NVP-BEZ235, a dual $\mathrm{PI} 3 \mathrm{~K} / \mathrm{mTOR}$ inhibitor, induces cell death through alternate routes in prostate cancer cells depending on the PTEN genotype. Apoptosis 19: 895-904, 2014.

10. Maira SM, Stauffer F, Brueggen J, Furet P, Schnell C, Fritsch C, Brachmann $\mathrm{S}$, Chène $\mathrm{P}$, De Pover $\mathrm{A}$, Schoemaker K, et al: Identification and characterization of NVP-BEZ235, a new orally available dual phosphatidylinositol 3-kinase/mammalian target of rapamycin inhibitor with potent in vivo antitumor activity. Mol Cancer Ther 7: 1851-1863, 2008.

11. Muranen T, Selfors LM, Worster DT, Iwanicki MP, Song L, Morales FC, Gao S, Mills GB and Brugge JS: Inhibition of $\mathrm{PI} 3 \mathrm{~K} / \mathrm{mTOR}$ leads to adaptive resistance in matrix-attached cancer cells. Cancer Cell 21: 227-239, 2012.

12. Dubrovska A, Kim S, Salamone RJ, Walker JR, Maira SM, García-Echeverría C, Schultz PG and Reddy VA: The role of PTEN/Akt/PI3K signaling in the maintenance and viability of prostate cancer stem-like cell populations. Proc Natl Acad Sci USA 106: 268-273, 2009.

13. Qian XJ, Li YT, Yu Y, Yang F, Deng R, Ji J, Jiao L, Li X, Wu RY, Chen WD, et al: Inhibition of DNA methyltransferase as a novel therapeutic strategy to overcome acquired resistance to dual PI3K/mTOR inhibitors. Oncotarget 6: 5134-5146, 2015.

14. Ishikawa C, Senba M and Mori N: Effects of NVP-BEZ235, a dual phosphatidylinositol 3-kinase/mammalian target of rapamycin inhibitor, on HTLV-1-infected T-cell lines. Oncol Lett 15: 5311-5317, 2018.

15. Wang D, Gao L, Liu X, Yuan C and Wang G: Improved antitumor effect of ionizing radiation in combination with rapamycin for treating nasopharyngeal carcinoma. Oncol Lett 14: 1105-1108, 2017.

16. Livak KJ and Schmittgen TD: Analysis of relative gene expression data using real-time quantitative PCR and the 2(-Delta Delta C(T)) method. Methods 25: 402-408, 2001. 
17. Ma BB, Lui VW, Hui CW, Lau CP, Wong CH, Hui EP, Ng MH, Cheng SH, Tsao SW, Tsang CM, et al: Preclinical evaluation of the mTOR-PI3K inhibitor BEZ235 in nasopharyngeal cancer models. Cancer Lett 343: 24-32, 2014.

18. Martini M, De Santis MC, Braccini L, Gulluni F and Hirsch E: PI3K/AKT signaling pathway and cancer: An updated review. Ann Med 46: 372-383, 2014.

19. Serra V, Markman B, Scaltriti M, Eichhorn PJ, Valero V, Guzman M, Botero ML, Llonch E, Atzori F, Di Cosimo S, et al: NVP-BEZ235, a dual PI3K/mTOR inhibitor, prevents PI3K signaling and inhibits the growth of cancer cells with activating PI3K mutations. Cancer Res 68: 8022-8030, 2008.

20. Guertin DA, Stevens DM, Thoreen CC, Burds AA, Kalaany NY, Moffat J, Brown M, Fitzgerald KJ and Sabatini DM: Ablation in mice of the mTORC components raptor, rictor, or mLST8 reveals that mTORC2 is required for signaling to Akt-FOXO and PKCalpha, but not S6K1. Dev Cell 11: 859-871, 2006.

21. Ocana A, Vera-Badillo F, Al-Mubarak M, Templeton AJ, Corrales-Sanchez V, Diez-Gonzalez L, Cuenca-Lopez MD, Seruga B, Pandiella A and Amir E: Activation of the $\mathrm{PI} 3 \mathrm{~K} / \mathrm{mTOR} / \mathrm{AKT}$ pathway and survival in solid tumors: Systematic review and meta-analysis. PLoS One 9: e95219, 2014.
22. Benjamin D, Colombi M, Moroni C and Hall MN: Rapamycin passes the torch: A new generation of mTOR inhibitors. Nat Rev Drug Discov 10: 868-880, 2011.

23. Ghayad SE, Bieche I, Vendrell JA, Keime C, Lidereau R, Dumontet $\mathrm{C}$ and Cohen PA: mTOR inhibition reverses acquired endocrine therapy resistance of breast cancer cells at the cell proliferation and gene-expression levels. Cancer Sci 99: 1992-2003, 2008.

24. Ma Y, Vassetzky Y and Dokudovskaya S: mTORC1 pathway in DNA damage response. Biochim Biophys Acta 1865: 1293-1311, 2018.

25. Balaji S, Ahmed M, Lorence E, Yan F, Nomie K and Wang M: NF-kappaB signaling and its relevance to the treatment of mantle cell lymphoma. J Hematol Oncol 11: 83, 2018.

26. Yang C, Peng J, Jiang W, Zhang Y, Chen X, Wu X, Zhu Y, Zhang $\mathrm{H}$, Chen J, Wang J, et al: mTOR activation in immature cells of primary nasopharyngeal carcinoma and anti-tumor effect of rapamycin in vitro and in vivo. Cancer Lett 341: 186-194, 2013.

(i) $\ominus$ This work is licensed under a Creative Commons Attribution-NonCommercial-NoDerivatives 4.0 International (CC BY-NC-ND 4.0) License. 